\title{
Synthesis of Fluoro-Aromatics by Balz-Schiemann Reaction -A Greener Approach
}

\author{
SURENDER KUMAR DHINGRA ${ }^{1^{*}}$, PURNIMA NAG ${ }^{2}$ and RAHUL SAXENA ${ }^{1}$ \\ ${ }^{1}$ Research and Development Centre, SRF Limited, Bhiwadi, Rajasthan-301019, India \\ ${ }^{2}$ Department of Chemistry, Jaipur National University, Jaipur-302017, India \\ surender.dhingra@srf.com
}

Received 15 September 2015 / Accepted 5 October 2015

\begin{abstract}
A greener approach for the preparation of fluoro-aromatics by diazotization of aromatic amines followed by thermal decomposition of derived tetrafluoroborate in ionic liquids has been developed. The advantages of this procedure are simplicity of reaction, no workup, high purity of the product, safer process, low waste effluents and commercializable processes with recyclability of ionic liquids.
\end{abstract}

Keywords: Green chemistry, Ionic liquid, Diazotization, Balz-Schiemann, Fluoro-aromatics, Aromatic amines

\section{Introduction}

The importance of fluorinated compounds for diverse applications in pharmaceuticals, agrochemicals, solvents, polymers, electronics and many more areas has now been well established ${ }^{1-3}$. Consequently, fluorination of organic molecules has become a very important target in various sectors.

The commonly known method for the regiospecific introduction of a fluorine atom to arenes is Balz-Schiemann reaction, a classical method for replacing the diazonium group of aryl diazonium salt ${ }^{4-6}$ with $\mathrm{HBF}_{4}$. The process of diazotization-fluorination is usually carried out in two steps: diazotization of amine in hydrochloric or sulphuric acid in presence of sodium nitrite at low temperature and subsequent reaction with fluoroborate ion. Second step involves decomposition of salt under conditions, which can be hazardous due to runaway reactions. The original drawback associated with classical Balz-Schiemann reaction is uncontrolled thermal decomposition of aryl diazonium fluoroborate salt. This safety consideration becomes more critical when reactions are carried out at large scale. This is probably one of the reasons that not many of Balz-Schiemann reactions have been commercialized. This drawback leads to the potential danger of explosion when large scale thermal decomposition of the aromatic diazonium tetrafluoroborates is attempted. Even though when the decomposition is carried out either thermally or photolytically ${ }^{7}$ in pyridineHF solution or other suitable solvents, the recovery of these solvents are very difficult due to the tarry residue generated in these reactions. 
Ionic liquids (ILs) have gained wide popularity in recent years, as many new applications of these compounds as reaction media for a wide variety of synthetic processes have been reported ${ }^{8-11}$. The last decade has witnessed a rapidly growing interest in various aspects of ionic liquids specially in chemical synthesis as recyclable solvents, reagents and catalysts $^{12-13}$. Ionic liquids such as 1-butyl-3-methylimidazolium tetrafluoroborate and 1-butyl-3-methylimidazolium hexa fluorophosphate have a broad application as green solvent $^{14-16}$ as these are highly thermal and electrochemically stable, and have negligible vapor pressure, relatively low viscosity and high density.

Laali and Gettwert reported fluoro-dediazoniation in ionic liquid ${ }^{17}$. Although, the reported study offers improvement over classical Balz-Schiemann reaction. It is more of academic interest. The reactions are performed on milligram scale and does not take care of the environmental concerns and scalability requirements for commercialization

\section{Experimental}

Raw materials were purchased from Sigma-Aldrich/ Spectrochem and used without further purification. IR spectra were recorded on a PERKIN ELMER infrared spectrophotometer. GCMS were recorded on 5975C inert XL MSD with Triple Axis Detector attached with 7890A GC system from AGILENT TEHNOLOGIES. Boiling points were analyzed on VEEGO instrument. GC purity were analyzed with HP-5 capillary column and authenticated with standard pure sample obtained from Sigma Aldrich. The GC data were reported in area percent. The synthesized compounds were characterized by ${ }^{1} \mathrm{H}$ NMR and ${ }^{19} \mathrm{~F}$ NMR recorded on Bruker $(500-\mathrm{MHz})$ instrument using $\mathrm{CDCl}_{3}$ as solvent.

\section{Preparation of ionic liquids}

The imidazolium based ionic liquids with aliphatic side chains i.e.1-butyl-3-methylimidazolium tetrafluoroborate (IL-1) and 1-butyl-3-methylimidazolium hexafluorophosphate (IL-2) were prepared according to the procedure described in literature ${ }^{18-20}$ (Scheme 1).

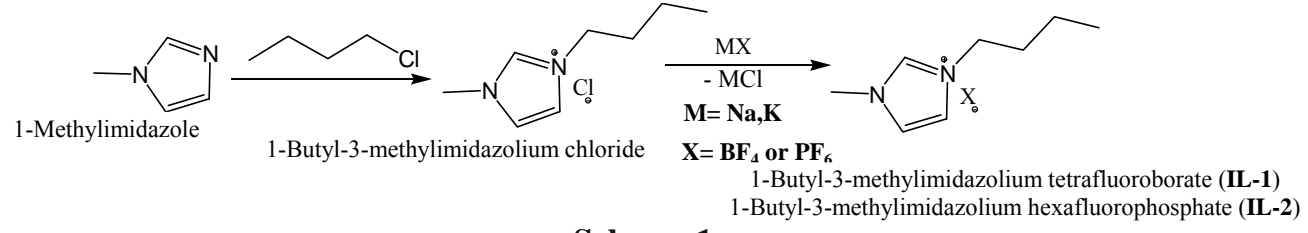

Scheme 1

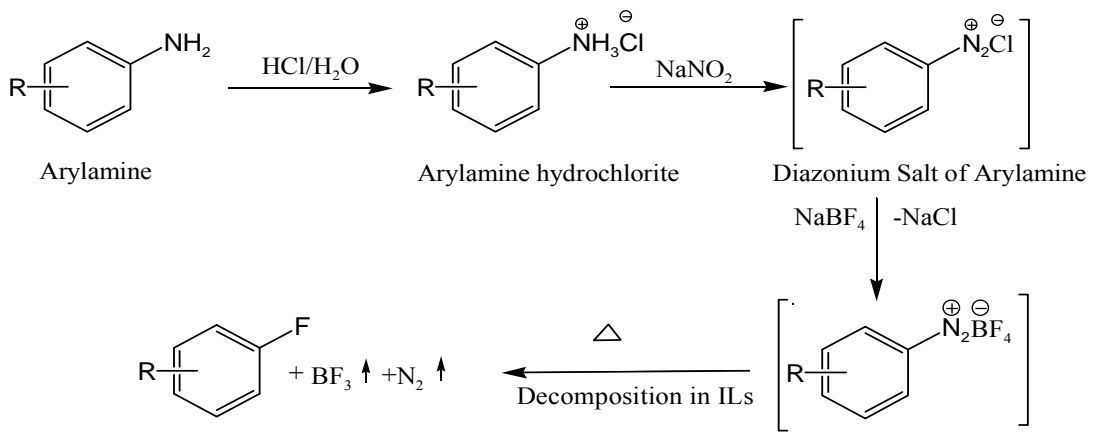

Floro aromatics compound

$\mathrm{R}=-\mathrm{H},-\mathrm{Cl},-\mathrm{F},-\mathrm{NO}_{2},-\mathrm{CF}_{3}$

Diazo Fluoroborate Salt

Scheme 2 


\section{General procedure for the synthesis of fluoro-aromatics}

In a typical experiment as shown in Scheme 2, 3-aminobenzotrifluoride $(0.06 \mathrm{~mol}, 10 \mathrm{~g})$ was dissolved in a dilute hydrochloric acid. The aqueous solution of $\mathrm{NaNO}_{2}(0.062 \mathrm{~mol}, 4.28 \mathrm{~g})$ was added to the reaction mixture at $0-5{ }^{\circ} \mathrm{C}$. Stirred for half an hour followed by addition of an aqueous solution of $\mathrm{NaBF}_{4}(0.062 \mathrm{~mol}, 6.81 \mathrm{~g})$ to form insoluble diazonium fluoroborate salt. The precipitated salt was filtered, washed with water, dried under vacuum to obtain benzene diazonium fluoroborate salt $(0.062 \mathrm{~mol}, 16.1 \mathrm{~g})$. The obtained salt was suspended in IL-1 (0.05 mol, $12.0 \mathrm{~g})$, stirred and heated at $80-85{ }^{\circ} \mathrm{C}$ for $3-6 \mathrm{~h}$ until dediazoniation was completed, the product was simultaneously distilled off to afford $8.9 \mathrm{~g}$ of product.

\section{3-Fluorobenzotrifluoride $(\mathbf{1})^{21}$}

Yield: $87.4 \%$, B.P. $100-102{ }^{\circ} \mathrm{C}$, Colorless liquid. IR $v_{\max }\left(\mathrm{cm}^{-1}\right): 1602,1493,1455,1327$, 1279, 1126, 1057, 891, 879, 745, 695, 521. GC-MS: ${ }^{1} \mathrm{H}$ NMR (500MHz, $\left.\mathrm{CDCl}_{3}\right): \delta 7.2-7.5$ (4H, m). ${ }^{19} \mathrm{~F}-\mathrm{NMR}\left(\mathrm{CDCl}_{3}\right): \delta-62.9(1 \mathrm{~F}, \mathrm{~s}),-111.0(3 \mathrm{~F}, \mathrm{~s})$. Molecular ion $\mathrm{m} / \mathrm{z}$ (int. \%) 164 (100), 146 (89), 95(56).

Fluorobenzene $(2)^{22}$

Yield: $93.2 \%$, B.P: $84-85{ }^{\circ}$ C, Purity (GC): $99.8 \% \operatorname{IR~} v_{\max }\left(\mathrm{cm}^{-1}\right): 2955,2924,2853,1462$, 1377. ${ }^{1} \mathrm{H}$ NMR $\left(500 \mathrm{MHz}, \mathrm{CDCl}_{3}\right): \delta 7.05(2 \mathrm{H}, \mathrm{m}), 7.15(1 \mathrm{H}, \mathrm{m}), 7.35(2 \mathrm{H}, \mathrm{m}) . \mathrm{GC}-\mathrm{MS}$ : Molecular ion $\mathrm{m} / \mathrm{z}$ (int. \%) 96 (100), 70 (31), 50 (22).

\section{1,4-Difluorobenzene(3) ${ }^{21}$}

Yield: $90 \%$, B.P. $88-90{ }^{\circ}$ C, Purity (GC): $99.3 \%$ IR $v_{\max }\left(\mathrm{cm}^{-1}\right): 1632,1501,1433,1199$, 1181, 1084, 1011, 829, 734, 635, 506. ${ }^{1} \mathrm{H}$ NMR (500MHz, $\left.\mathrm{CDCl}_{3}\right): \delta 7.0$ (4H, dd). GC-MS: Molecular ion $\mathrm{m} / \mathrm{z}$ (int. \%) 114 (100), 94 (82), 63 (55).

\section{1,2,4-Trifluorobenzene $(4)^{22}$}

Yield: $68 \%$, B.P: $90-91{ }^{\circ} \mathrm{C}$, Purity (GC): $99.9 \%$ IR $v_{\max }\left(\mathrm{cm}^{-1}\right): 2957,2925,2853,1516$, 1458, 1377. ${ }^{1} \mathrm{H}$ NMR $\left(500 \mathrm{MHz}, \mathrm{CDCl}_{3}\right): \delta 6.8(1 \mathrm{H}, \mathrm{m}), 6.9(1 \mathrm{H}, \mathrm{m}), 7.15(1 \mathrm{H}, \mathrm{m})$. GC-MS: Molecular ion $\mathrm{m} / \mathrm{z}$ (int. \%) 132 (100), 81 (18), 63 (26).

\section{4-Nitrofluorobenzene $(5)^{23}$}

Yield: $86.7 \%$, B.P: $204-205{ }^{\circ} \mathrm{C}$, Purity (GC): $99.9 \% \operatorname{IR} v_{\max }\left(\mathrm{cm}^{-1}\right): 3122,3090,1915,1620$, 1592, 1520, 1493, 863, 851, 747, 680, 616, 491. ${ }^{1} \mathrm{H}$ NMR $\left(500 \mathrm{MHz}, \mathrm{CDCl}_{3}\right): \delta 7.1(2 \mathrm{H}, \mathrm{m})$, 8.2 (2H, m). GC-MS: Molecular ion $\mathrm{m} / \mathrm{z}$ (int.\%) 141 (100), 111.1 (42), 75 (87), 50 (17).

\section{1-Fluoronaphthalene $(6)^{24}$}

Yield: $72 \%$, B.P: $214{ }^{\circ}$ C, Purity (GC): $99.9 \%$ IR $v_{\max }\left(\mathrm{cm}^{-1}\right): 3061,1916,1641,1600,1229$, 1261, 1074, 790, 762, 563, 413. ${ }^{1} \mathrm{H}$ NMR $\left(500 \mathrm{MHz}, \mathrm{CDCl}_{3}\right): \delta 7.1(1 \mathrm{H}, \mathrm{m}), 7.3-7.6(4 \mathrm{H}$, m), $7.8(1 \mathrm{H}, \mathrm{m}), 8.1$ (1H, m). GC-MS: Molecular ion $\mathrm{m} / \mathrm{z}$ (int. \%) 146 (100), 120 (14), 99 (6).

\section{Results and Discussion}

The ionic liquids 1-butyl-3-methylimidazolium tetrafluoroborate (IL-1) and 1-butyl-3methylimidazolium hexafluorophosphate (IL-2) were used for fluoro-dediazoniation depending upon the solubility of prepared diazonium salt. The prepared aryl diazonium salts are stable at room temperature and completely soluble in IL-1 and IL-2, they are transformed to corresponding aryl fluorides in excellent to very good yields after their thermal decomposition in ionic liquids. The reactions were completed in 4-6 h. None of the reactions indicated runaway reaction tendencies. The problem of sudden exotherm, 
low yield and formation of tarry bottom residue are overcomes by the present protocol. The obtained products are high in purity and need not require further purification while the byproduct of reaction such as boron trifluoride gas can be trapped in ether to form $\mathrm{BF}_{3}$-etherate, a useful lewis acid. Several fluoro-dediazoniation reactions were performed as mentioned in Table 1. The process involves a heterolytic mechanism for thermal decomposition where an aryl cation directly reacts with tetrafluoroborate anion via a tight ion pair.

Table 1. Synthesis of aryl fluorides from aryl amines in the presence of ionic liquids

\begin{tabular}{|c|c|c|c|c|c|c|c|}
\hline $\begin{array}{c}\text { Entry } \\
\text { No. }\end{array}$ & Substrate & Product & $\begin{array}{c}\text { Time } \\
\mathrm{h}\end{array}$ & $\begin{array}{c}\text { Temp } \\
{ }^{\circ} \mathrm{C}\end{array}$ & $\begin{array}{c}\text { Yield } \\
\% \\
\end{array}$ & $\begin{array}{c}\text { Purity, } \\
\%\end{array}$ & $\begin{array}{l}\mathrm{ILs}^{\#} \\
\text { Used }\end{array}$ \\
\hline 1 & & & 6 & 100 & 87.4 & 99.3 & 1,2 \\
\hline 2 & & & 4 & 85 & 93.2 & 99.8 & 1 \\
\hline 3 & & & 4 & 88 & 90 & 99.3 & 1 \\
\hline 4 & & & 5 & 90 & 68 & 99.9 & 1,2 \\
\hline 5 & & & 4.5 & $91^{*}$ & 86.7 & 99.9 & 1,2 \\
\hline 6 & & & 5 & $100^{*}$ & 72 & 99.9 & 1,2 \\
\hline $7^{* *}$ & & & -- & -- & -- & -- & 1 \\
\hline $8^{* * *}$ & & & -- & -- & -- & -- & 1 \\
\hline
\end{tabular}

${ }^{*}$ At $740 \mathrm{mmHg},{ }^{* *}$ Expected product 4-fluorophenol not formed as diazonium salt of 4-aminophenol was soluble in water., ${ }^{* * *}$ Expected product hexafluorobenzene not formed. "Ionic liquid used for dediazoniation 
Monofluoro, difluoro and trifluoro substituted aromatic compounds (entries 2-4) were prepared by the above process. It was observed that as the number of substituted fluorine atoms increases in the ring, the tendency of deamination of tetrafluoroborate complex increases resulting in lower yield.

It was also observed that phenolic compounds like 4-nitrophenol, 2,4-dinitrophenol do not undergo fluoro-dediazoniation as their diazonium tetrafluoroborate salt are soluble in water and are difficult to separate while diazonium salt of 2,3,4,5,6-pentafluoroaniline on decomposition in IL-1 did not gave the expected hexafluorobenzene. The detailed examination of the reaction mixture indicates the presence of 2,3,5,6,-tetrafluorophenol, $2,3,4,5,6$ pentafluorobenzene and decafluorodiazoamino-benzene as major products ${ }^{25-27}$.

The ionic liquid (IL-1) was reused for several runs (Table 2) without regeneration. Synthesis of fluorobenzene was used as a model for this study. The purity of isolated product was not significantly affected, however, there was slight decrease in yield was observed with each subsequent run. After several (5-6) runs, the effluent load increased in ionic liquid due to the accumulation of decomposed by-products which can be removed by washing it with a suitable solvent like methylene chloride.

Table 2. Recycling of ionic liquid (IL-1) 1-butyl-3-methylimidazolium tetrafluoroborate for the synthesis of fluorobenzene from benzene diazonium tetrafluoroborate

\begin{tabular}{ccc}
\hline No. of cycles & Yield, \% & Purity, \% \\
\hline 1 & 93.2 & 99.8 \\
2 & 90.4 & 99.8 \\
3 & 88.8 & 99.5 \\
4 & 88.4 & 99.4 \\
5 & 87.6 & 99.3 \\
6 & 86.1 & 99.3 \\
\hline
\end{tabular}

The reported fluoro-dediazoniation in ionic liquid by Laali and Gettwert is unsuitable for commercialization. It requires organic solvent diethyl-ether for isolation of the product and also requires addition of Hunig's base to control the associated side reactions ${ }^{17}$. The Hunig's base adds to the cost and requires neutralization with acid before disposal. A rough estimate indicates that 11.5 tons of effluents will be generated for each ton of fluoroaromatic produced by the above process. Thus the process is neither green nor commercializable.

We found that, ionic liquids, if selected wisely, can be a solvent of choice for fluorination reaction especially for large scale fluoro-dediazoniation reactions. The waste generated during workup and subsequent purification by column chromatography was avoided by the use of ionic liquids. Besides, the ionic liquids provided excellent medium to control the exothermicity of Balz-Schiemann reaction. Advantage was taken of volatility of fluorinated products, they were distilled out immediately upon their formation. This prevented their decomposition at high temperature of reaction, thus avoiding the need for addition of a base and subsequent purification. The products were obtained in high yield and purity. Since no organic solvent is required for their isolation and subsequent purification, the reactions are efficient, greener and suitable for large scale operations.

\section{Conclusion}

We have developed a new and highly efficient green reaction protocol for the synthesis of fluoro aromatics using fluoro-dediazoniation in ionic liquids. Safety and recyclability of ionic liquids for several runs makes the process suitable for commercialization. High purity, shorter 
reaction time, low effluents and simple workup procedure than the classical methods of fluorination are also appealing attributes of this work.

\section{Acknowledgement}

Author thanks Jaipur National University, Jaipur, Rajasthan, India for providing necessary facilities and support.

\section{References}

1. Fustero S, Soloshonok V A and Liu H, Chem Rev., 2014, 114(4), 2432-2506; DOI:10.1021/cr4002879

2. Zhao H and Malhotra S V, Aldrichem Acta, 2002, 35(3), 75-83.

3. Banks R E, Smart B E and Tatlow J C, Organo-fluorine Chemistry; Principles and Commercial Applications, Plenum Press, New York, USA. 1994, 237.

4. Balz G and Schiemann G, Chem Ber., 1927, 60(5), 1186-1190; DOI:10.1002/cber.19270600539

5. Michael P D and William J B, J Org Chem., 1979, 44(9), 1572-1574; DOI:10.1021/jo01323a048

6. $\quad$ Bergmann E D, Berkovic S and Ikan R, J Am Chem Soc., 1956, 78(23), 6037-6039; DOI:10.1021/ja01604a023

7. Cohen L A and Kirk K L, J Am Chem Soc., 1971, 93(12), 3060-3061; DOI:10.1021/ja00741a048

8. Welton T, Chem Rev., 1999, 99, 2071-2084; DOI:10.1021/cr980032t

9. $\quad$ Earle M J and Seddon K R, Pure Appl Chem., 2000, 72(7), 1391.

10. Chiappe C and Pieraccini D, J Phys Org Chem., 2005, 18(4), 275-297; DOI:10.1002/poc.863

11. Jindal R and Sablok A, Current Green Chem., 2015, 2(2), 135-155; DOI:10.2174/2213346101666140915212515

12. Wasserscheid $\mathrm{P}$ and Welton, T Ionic Liquids in Synthesis; Wiley-VCH, Germany, 2002, 174.

13. Pârvulescu V I and Hardacre C, Chem Rev., 2007, 107(6), 2615-2665; DOI:10.1021/cr050948h

14. Earle M J, Mc Cormac P B and Seddon K R, J Chem Soc Chem Comm., 1998, 20, 2245.

15. Mc Ewen A B, Ngo H L, Le Compte K and Goldman J L, J Electrochem Soc., 1999, 146(5), 1687-1695; DOI:10.1149/1.1391827

16. Armstrong D W, He L and Liu Y S, Anal Chem., 1999, 71(17), 3873-3876; DOI:10.1021/ac990443p

17. Laali K K and Gettwert V J, J Fluorine Chem., 2001, 107(1), 31-34; DOI:10.1016/S0022-1139(00)00337-7

18. Wilkes J S and Zaworotko M J, J Chem Soc., Chem Comm., 1992, 13, 965-967; DOI:10.1039/C39920000965

19. Willis E D and Creary X, Org Syn., 2005, 82, 166-169.

20. De Souza R F, Dupont J, Consorti S C and Suarez P A Z, Org Syn Coll., 2004, 10, 184.

21. Dubbaka S R, Narreddula V R, Gadde S and Mathew T, Tetrahedron, 2014, 70(51), 9676-9681; DOI:10.1016/j.tet.2014.10.055

22. Yu C M, Yu Z Q, Lv Y W and Su W K, Tetrahedron Lett., 2013, 54(10), 1261-1263; DOI:10.1016/j.tetlet.2012.12.084

23. Ritter T, Tang P and Wang W, J Am Chem Soc., 2011, 133(30), 11482-11484; DOI:10.1021/ja2048072 
24. Ritter T, Weike W and Furuya T, Org Lett., 2009, 11(13), 2860-2863; DOI:10.1021/o1901113t

25. Wall L A, Pummer W J, Fearn J E and Antonucci J M, J Res NBS., 1963, 67A, 481-497.

26. Brooke G M, Forbes E J, Richardson R D, Stacey M and Tatlow J C, J Chem Soc., 1965, 2088-2094.

27. Kobayashi H, Iwamoto H and Sonoda T, J Fluorine Chem.., 1984, 24(4), 535-537; DOI:10.1016/S0022-1139(00)83174-7 